\title{
Protective effect of autophagy in neural ischemia and hypoxia: Negative regulation of the $\mathrm{Wnt} / \boldsymbol{\beta}$-catenin pathway
}

\author{
ZHEN-YU SHI ${ }^{1,2}$, JIE-XIN DENG $^{1}$, SU FU $^{1}$, LAI WANG $^{2}$, QIANG WANG $^{1}$, \\ BIN LIU ${ }^{1}$, YONG-QIANG LI ${ }^{1}$ and JIN-BO DENG ${ }^{1,2}$ \\ ${ }^{1}$ Institute of Neurobiology, Nursing College, Henan University; ${ }^{2}$ Institute of Neurobiology, \\ College of Life Science, Henan University, Kaifeng, Henan 475004, P.R. China
}

Received February 2, 2017; Accepted September 26, 2017

DOI: $10.3892 / \mathrm{ijmm} .2017 .3158$

\begin{abstract}
Autophagy is a highly conserved process of selfdigestion to promote cell survival in response to nutrient starvation and other metabolic stresses. However, whether ischemic-hypoxic (IH) injury-induced autophagy acts as a neuroprotective mechanism or leads to neuroinjury is a subject of debate. It is known that autophagy is regulated by signaling pathways, including the mammalian target of rapamycin pathway. However, in neural IH injury, whether other signaling pathways are involved in the regulation of autophagy remains to be fully elucidated. In the present study, using the autophagy agonist (rampycin), autophagy antagonist [3-methyl adenine (3-MA)] and lysosome antagonist (MHY1485), autophagy was intervened with at oxygen-glucose deprivation (OGD) $6 \mathrm{~h}$, in order to elucidate the regulatory mechanisms of autophagy. Using immunocytochemistry and western blot analysis, the expression levels of stress-related proteins, such as hypoxia-inducible factor- $1 \alpha$ (HIF-1 $\alpha$ ) (a key regulator in hypoxia) and cyclooxygenase 2 (COX2; inflammatory indicator), were analyzed. In addition, the upstream proteins (Wnt1 and Wnt3a), downstream proteins (Dvl2, $\beta$-catenin) and target proteins (C-myc and cyclin $\mathrm{D}$ ) in the Wnt/ $\beta$-catenin signaling pathway were examined by immunocytochemistry and western blot analysis. The present study revealed that autophagy was activated with the upregulation of autophagic flux in IH injury; it was demonstrated that autophagy had a protective role in IH injury. The Wnt/ $\beta$-catenin pathway was involved in IH injury regulation, and the upstream proteins in the $\mathrm{Wnt} / \beta$-catenin signaling pathway were upregulated,
\end{abstract}

Correspondence to: Dr Yong-Qiang Li, Institute of Neurobiology, Nursing College, Henan University, 1 Jinming Road, Kaifeng, Henan 475004, P.R. China

E-mail: hdlyq@foxmail.com

Dr Jin-Bo Deng, Institute of Neurobiology, College of Life Science, Henan University, 1 Jinming Road, Kaifeng, Henan 475004, P.R. China E-mail: jinbo_deng@henu.edu.cn

Key words: autophagy, Wnt signaling, ischemic and hypoxic injuries, inflammation, oxygen and glucose deprivation whereas downstream proteins were downregulated by the activity of autophagy accordingly.

\section{Introduction}

Stroke is a neural degenerative disease with high rates of mortality and disability, which is characterized by ischemichypoxic (IH) injury in neurons (1). Strokes are classified as ischemic and hemorrhagic, with $\sim 80 \%$ of cases being ischemic (2). Ischemic stroke is induced by a sudden reduction of blood circulation, resulting in the cutoff of oxygen to the brain and corresponding loss of neurological function. Ischemic stroke can lead to permanent and transient IH injuries, depending on crucial artery reperfusion within a limited period of time, with permanent IH dominant in clinic cases. The pathological processes of IH injury include hypoxia response, postischemic inflammatory response, cell apoptosis and peri-infarct depolarization (3-5).

Although stroke has attracted widespread attention clinically, effectiveness of treatment is finite, as the mechanism underlying IH injury remains to be fully elucidated. Previous studies have revealed that autophagy is important in inflammation, nutrient deprivation and the processes of IH. For example, studies have indicated that autophagy is involved in IH injury affecting neuronal survival following chronic and moderate hypoxia (6). However, considering the existence of cell death during autophagic processes, how autophagy mediates neuronal survival following IH injury remains a topic of debate, particularly in permanent IH injury (7-11). Autophagy involves a cascade of morphological and chemical processes, with the involvement of several apoptotic proteins and signaling transduction pathways, including Beclin 1 and autophagy-related (Atg) proteins, and the Notch pathway. Previous studies have shown that the Wnt signaling pathway is also involved in autophagy (12-15), despite the Wnt signaling pathway being involved primarily in the regulation of cell proliferation and differentiation during development $(16,17)$. In addition, previous studies have shown that the Wnt signaling pathway is likely to be important in the pathogenesis of neurodegenerative diseases, including $\mathrm{IH}$, as cytokines in the Wnt pathway can improve the microenvironment of neuronal repair following post-ischemic injury (18). However, how the Wnt signaling pathway regulates autophagy in permanent neuronal 
IH injury remains to be fully elucidated, particularly the role of autophagic flux in regulation.

In the present study, PC12 cells were used to establish an oxygen-glucose deprivation (OGD) model to imitate permanent IH injury. Following the induction of autophagy in the IH model, the expression levels of hypoxia-inducible factor- $\alpha$ (HIF- $\alpha)$, a key regulator in hypoxia, and cyclooxygenase 2 (COX2), an inflammatory indicator, were investigated. The apoptotic rates of cells and levels of lactate dehydrogenase (LDH) were also analyzed (19), and the role of autophagy during IH injury and the regulatory mechanism of the Wnt pathway in autophagy were discussed. The data may provide novel insight for treatment strategies following stroke.

\section{Materials and methods}

\section{Cell culture and the model of $O G D$}

Cell culture. As a neuronal alternative, PC12 cells, obtained from the Institute of Cell Biology, Chinese Academy of Sciences (Shanghai, China) were used in the present study as a neuronal model. Following thawing, the PC12 cells on collagen-coated glass were cultured in normal medium containing Dulbecco's modified Eagle's medium (cat. no. 12800-017; Thermo Fisher Scientific, Inc., Waltham, MA, USA) supplemented with 5\% fetal bovine serum (FBS; Zhejiang Tiangeng Biotechnology, Zhejiang, China), 5\% heat-inactivated horse serum (cat. no. 26050070; Thermo Fisher Scientific, Inc.), 50 U/ml penicillin and $50 \mu \mathrm{g} / \mathrm{ml}$ streptomycin. The cells were cultured at $37^{\circ} \mathrm{C}$ with $5 \% \mathrm{CO}_{2}$ for 2 days, following which the cells were harvested in the log phase with neuron-like morphology and at $70-80 \%$ cell confluence.

OGD treatment. Initially, Biocoat plates were precoated with poly-D-lysine (BD Biosciences, Bedford, MA, USA), and the PC12 cells were plated at the density of $1 \times 10^{4}$ cells/well in the 24-well culture plate. The PC12 cells were grown for $12 \mathrm{~h}$ in normal medium (DMEM with $5 \%$ heated horse serum and $5 \% \mathrm{FBS}$ ) at $37^{\circ} \mathrm{C}$ with $5 \% \mathrm{CO}_{2}$. For OGD treatment, the cells were rinsed twice in DMEM without glucose (cat. no. 11966-025; Thermo Fisher Scientific, Inc.), following which they were transferred into modular incubator chambers (Billups-Rothenberg, Del Mar, CA, USA) with OGD medium (glucose-free DMEM with 2\% horse serum and 1\% FBS). The chambers were perfused with $95 \% \mathrm{~N}_{2}$ and $5 \% \mathrm{CO}_{2}$ for $30 \mathrm{~min}$ and $3 \mathrm{l} / \mathrm{min}$ speed at room temperature. Finally, the chambers were sealed and cultured at $37^{\circ} \mathrm{C}$ for designated durations $(0.5$, $1,6,12$ and $24 \mathrm{~h}$ ), respectively.

Cell grouping. In order to understand the effect of time on IH injury and autophagy, the cells were divided into a control group, in which cells were cultured in normal medium under normoxia, and OGD groups, in which cells were cultured in OGD medium for $0.5 \mathrm{~h}(\mathrm{OGD}+0.5 \mathrm{~h}), 2 \mathrm{~h}(\mathrm{OGD}+2 \mathrm{~h})$, $6 \mathrm{~h}(\mathrm{OGD}+6 \mathrm{~h}), 12 \mathrm{~h}(\mathrm{OGD}+12 \mathrm{~h})$ and $24 \mathrm{~h}(\mathrm{OGD}+24 \mathrm{~h})$. The $0.5,2$ and $6 \mathrm{~h}$ time-points represented the condition of transient IH, whereas the 12 and $24 \mathrm{~h}$ time-points represented permanent IH. In the present study, autophagy was examined at the various time-points under OGD conditions and following chemical intervention (20), including exposure to rapamycin (RAP; autophagy agonist), 3-methyladenine (3-MA; autophagy antagonist) and MHY1485 (MHY; lysosome antagonist). In these intervention groups, the cells were first cultured in normal medium containing the respective intervention agents at $37^{\circ} \mathrm{C}$ for $2 \mathrm{~h}$, followed by continuous culture under OGD conditions for $6 \mathrm{~h}$. The intervention agents and their doses were as follows: $10 \mu \mathrm{M}$ rapamycin (RAP+OGD), $10 \mathrm{mM}$ 3-MA (3-MA+OGD) and $2 \mu \mathrm{M} \mathrm{MHY}$ (MHY+OGD).

\section{Assays for neuronal injury}

3-(4,5-Dimethylthiazol-2-yl)-2,5-diphenyltetrazolium bromide (MTT) assay. The cells were seeded at a density of $1 \times 10^{4}$ cells $/ \mathrm{ml}$ in 96-well culture plates. After $24 \mathrm{~h}$, the cells were treated with the OGD treatment. Control wells consisted of cells incubated with medium only. Following the different durations of treatment, the cells were incubated with $20 \mu \mathrm{l} \mathrm{MTT}(5 \mathrm{mg} / \mathrm{ml}$; Sigma; Merck Millipore, Darmstadt, Germany). After $4 \mathrm{~h}$ at $37^{\circ} \mathrm{C}$, the supernatant was removed and $150 \mu \mathrm{l}$ dimethyl sulfoxide (DMSO) was added. The blue crystals were dissolved in DMSO and the optical density (OD) was detected at a wavelength of $570 \mathrm{~nm}$ using a 96-well multiscanner autoreader (Bio-Rad Laboratories, Inc., Hercules, CA, USA). The following formula was used: Cell proliferation inhibition $(\%)=[1-($ OD of experimental sample/OD of control $)] \times 100$.

LDH analysis for necrosis. The cells were seeded at $1 \times 10^{6}$ cells in 6-well Biocoat plates. As necrotic cells can release $\mathrm{LDH}$, the quantity of $\mathrm{LDH}$ can be used to evaluate the condition of cell death. Following the collection of culture medium and centrifugation at the speed in $250 \mathrm{x}$ g for $10 \mathrm{~min}$ at $4^{\circ} \mathrm{C}$, the supernatant was obtained. Using the LDH assay kit (Sigma; Merck Millipore), the supernatant was incubated with $100 \mu \mathrm{l}$ substrate buffer/well for $30 \mathrm{~min}$ at $37^{\circ} \mathrm{C}$. Following centrifugation at the speed in $250 \mathrm{x}$ g for $10 \mathrm{~min}$ at room temperature, cellular debris was removed, and LDH was assessed at $490 \mathrm{~nm}$ excitation. The LDH value was calculated according to the following formula: $\mathrm{LDH}=$ (sample OD value - control OD value)/(standard OD value - blank control OD) $\mathrm{x}$ standard substance concentration $\mathrm{x} 1,000 \mathrm{U} / \mathrm{l}$. The percentage $\mathrm{LDH}$ was calculated to reflect the condition of cell death. The percentage LDH was calculated as: sample LDH value/control $\mathrm{LDH}$ value.

Western blot analysis. The proteins were extracted from the PC12 cells using RIPA buffer, containing $20 \mathrm{mmol} / \mathrm{l}$ Tris- $\mathrm{HCl}$ ( $\mathrm{pH} 7.5$ ), $150 \mathrm{mmol} / \mathrm{l} \mathrm{NaCl}, 1 \mathrm{mmol} / \mathrm{LEDTA}$, 1\% Triton X-100 (cat. no. T0694; Sangon Biotech Co., Ltd., Beijing, China) and $1 \mathrm{mmol} / \mathrm{l}$ PMSF. Protein concentrations were determined by a reducing agent-compatible BCA assays kit (Pierce, Nepean, ON, Canada). The proteins $(30 \mu \mathrm{g})$ were separated on 10 or $15 \%$ sodium dodecyl sulfate-polyacrylamide gel electrophoresis (SDS-PAGE) gels and transferred onto a polyvinylidene difluoride membrane (EMD Millipore, Billerica, MA, USA). Following blocking with 5\% skim milk in Tris-buffered saline, the membrane was incubated with primary antibodies at $4^{\circ} \mathrm{C}$ overnight. The following primary antibodies were used: Rabbit polyclonal anti-microtubuleassociated protein 1A/1B-light chain 3 (MAP1LC3A; 1:1,500; cat. no. ab52768), mouse monoclonal anti-HIF- $\alpha$ (1:1,500, cat. no. ab16066) (both from Abcam, Cambridge, UK), mouse monoclonal anti protein-COX2 (1:1,000; cat. no. sc166475), goat polyclonal anti-Beclin 1 (1:1,000; cat. no. sc10086) (both from Santa Cruz Biotechnology, Inc., Dallas, TX, USA), mouse monoclonal anti-sequestosome (SQSTM1/p62; 1:1,000; 
cat. no. ab56416), rabbit polyclonal anti-Wnt1 (1:1,000; cat. no. ab15251), rabbit polyclonal anti-Wnt3a (1:1,500; cat. no. ab19925), rabbit polyclonal anti- $\beta$-catenin (1:1,000; cat. no. ab6302) (all from Abcam), mouse polyclonal anti-dishevelled segment polarity protein 2 (Dvl2; 1:800; cat. no. 12037-1-AP; ProteinTech Group, Inc., Chicago, IL, USA), mouse monoclonal anti-cyclin D1 (A-12; 1:1,000; cat. no. sc8396; Santa Cruz Biotechnology, Inc.), rabbit polyclonal anti-C-myc (1:800; cat. no. 10828-1-AP; ProteinTech Group, Inc.). Following washing, secondary antibodies conjugated with horseradish peroxidase were added. Anti-rabbit (1:4,000; cat. no. ab6721), anti-mouse (1:4,000; cat. no. ab6728) or anti-goat IgGs (1:4,000; cat. no. ab6741) (all from Abcam) were used for $1 \mathrm{~h}$ at room temperature. Visualization of the immunoreactive bands was visualized with an enhanced chemoluminescence detection kit (Amersham; GE Healthcare Life Sciences, Piscataway, NJ, USA). $\beta$-actin (1:6,000; cat. no. a2228; SigmaAldrich; Merck Millipore) was used as an internal reference, and quantification of the intensities (target protein/ $\beta$-actin) of the immunoreactive bands was performed using ImageJ 10.0 software (National Institutes of Health, Bethesda, MA, USA).

Immunocytochemistry. The cells were fixed with $4 \%$ paraformaldehyde in phosphate buffer, and rinsed with $0.01 \mathrm{M}$ phosphate buffer, following which nonspecific antigens were blocked with $10 \%$ normal goat serum with $0.3 \%$ Triton X-100 and $1 \% \mathrm{BSA}$ in $0.01 \mathrm{M}$ phosphate buffer for $30 \mathrm{~min}$ at room temperature. The cells were incubated with primary antibodies at $4^{\circ} \mathrm{C}$ overnight. Following rinsing with phosphate-buffered saline (PBS) three times, each time for $10 \mathrm{~min}$, the cells were incubated with secondary antibodies for $3 \mathrm{~h}$ at room temperature. The primary antibodies were as follows: Rabbit anti-microtubule-associated LC3 (1:200; cat. no. sc28266; Santa Cruz Biotechnology, Inc.) polyclonal antibody, mouse anti-HIF- $\alpha$ (1:200; cat. no. ab16066; Abcam) monoclonal antibody, and mouse anti-COX2 (1:200; cat. no. sc166475; Santa Cruz Biotechnology, Inc.) monoclonal antibody. The secondary antibodies used were Alexa Fluor 488-conjugated anti-rabbit IgG (1:600; cat. no. a11034; Invitrogen; Thermo Fisher Scientific, Inc.) and Alexa Fluor 568-conjugated antimouse IgG (1:300; cat. no. a10037; Invitrogen; Thermo Fisher Scientific, Inc.). The cells were coverslipped with $65 \%$ glycerol in $0.01 \mathrm{M}$ phosphate buffer with DAPI $(1: 2,000)$ for counterstaining. Finally, images of the cells were captured with an epifluorescence microscope (BX61; Olympus Corp., Tokyo, Japan) under rhodamine, fluorescein isothiocyanate or ultraviolet excitation. Images of high quality sections were captured under a laser confocal microscope (FV1000; Olympus Corp.).

Measurements and statistical tests. In order to understand the levels of cell apoptosis and cell death, the levels of LDH and the apoptotic rates of the cells were quantified: i) Autophagic rate $(\%)=$ LC3-positive apoptotic cells/total cells; ii) levels of $\mathrm{LDH}$ were determined to evaluate the presence of necrosis as LDH $(\%)=$ sample $\mathrm{LDH}$ value/control LDH value; iii) using immunochemistry, fluorescent intensity was used for measuring expression levels of proteins, including COX2 and HIF- $\alpha$, as fluorescent intensity $=\Sigma$ positive cells IOD $/ \Sigma$ cells.

Statistical analysis. All data were analyzed in a double-blinded manner. Data are shown as the mean \pm standard deviation. Comparisons were made among various groups using one-way analysis of variance and were analyzed using the SPSS statistical package (SPSS 13.0; IBM SPSS, Armonk, NY, USA). $\mathrm{P}<0.05$ was considered to indicate a statistically significant difference.

\section{Results}

OGD and autophagic flux. In the present study, PC12 cell autophagy and autophagic flux were investigated following OGD treatment. LC3 was used to label the autophagosome in autophagic cells. In the control group, it was difficult to identify LC3-positive puncta in the PC12 cells (Fig. 1A), however, in OGD groups between 0.5 and $24 \mathrm{~h}$, dense LC3-positive puncta were found in the cytoplasm surrounding the nucleus. The expression levels of proteins LC3-II, LC3-I, Beclin 1 and p62, which reflect autophagic flux, were examined using western blot analysis (Fig. 1B-F). In the presence of autophagy, LC3-I in the cytoplasm is converted to LC3-II, which moves to the membrane of autophagosomes (21) (Fig. 1B). In the present study, the levels of LC3-II/I in the OGD groups were significantly increased in a dose-dependent manner $(\mathrm{P}<0.05)$, compared with those in the control group (Fig. 1B and D). The protein expression levels of p62 and Beclin 1 were also examined by western blot analysis. Compared with the control, the expression of p62 was decreased, however, the expression of Beclin 1 was increased and showed a similar trend in expression with LC3 in the OGD groups, with timedependency (Fig. 1B, C, E and F).

Autophagic intervention and function during IH. Using western blot analysis and immunochemistry, the present study revealed that the activation of autophagy was controlled under an autophagic flux during IH. Subsequent investigations were performed to examine the neural protective role of autophagy during IH. This was examined using an agonist and antagonist of autophagy, RAP and 3-MA, respectively, which were added to the OGD group (OGD+6 h). The neural protection of autophagy was evaluated through the expression levels of inflammatory and stress response factors, HIF- $\alpha$ and COX2. As OGD treatment for $6 \mathrm{~h}$ is considered the beginning of chronic IH injury, it shows marked injury. Therefore, in the present study, OGD for $6 \mathrm{~h}$ was used for the intervention experiment to observe autophagy. In the RAP+OGD group (Fig. 2A), autophagy was enhanced, with numerous LC3-II-positive puncta, which represented autophagosomes appearing in the cell soma, and the expression levels of HIF- $\alpha$ and COX2 were decreased (Fig. 2). In contrast to the RAP+OGD group, autophagy in the 3-MA+OGD group was significantly inhibited, with an increase in the expression levels of HIF- $\alpha$ and COX2 (Fig. 2). The results of the western blot analysis confirmed the results obtained from the immunochemistry experiments (Fig. 3A-D).

Lysosomes are important in autophagy, as the protein complexes and organelles in autophagosomes can be degraded by lysosomes (22). Accordingly, the lysosomal inhibitor MHY was used as an intervention for autophagy in the OGD group in the present study. Following MHY intervention, the autophagy in the PC12 cells was inhibited (Figs. 2 and 3A-D), suggesting that lysosomal suppression alleviated IH injury. The results of the $\mathrm{LDH}$ assay also showed that $\mathrm{LDH}$ release 
A
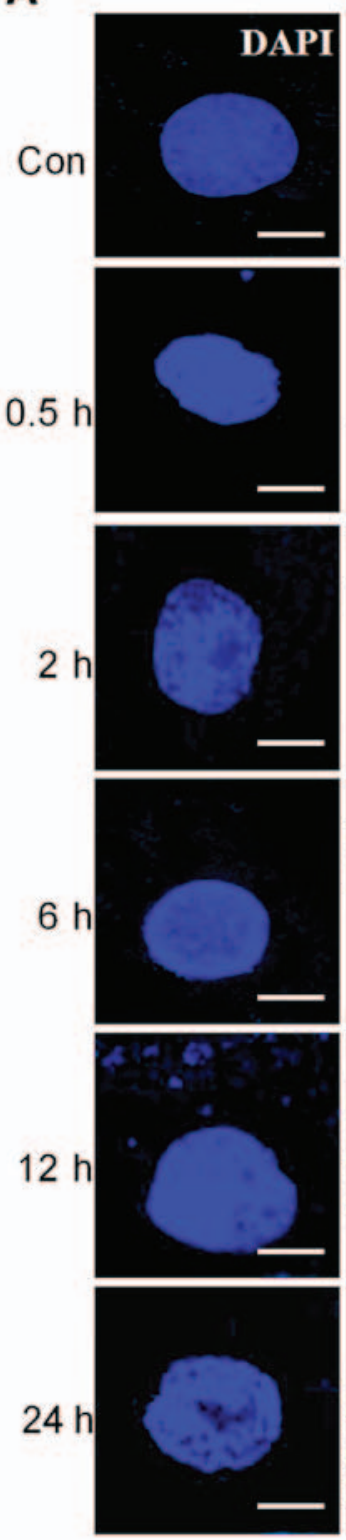
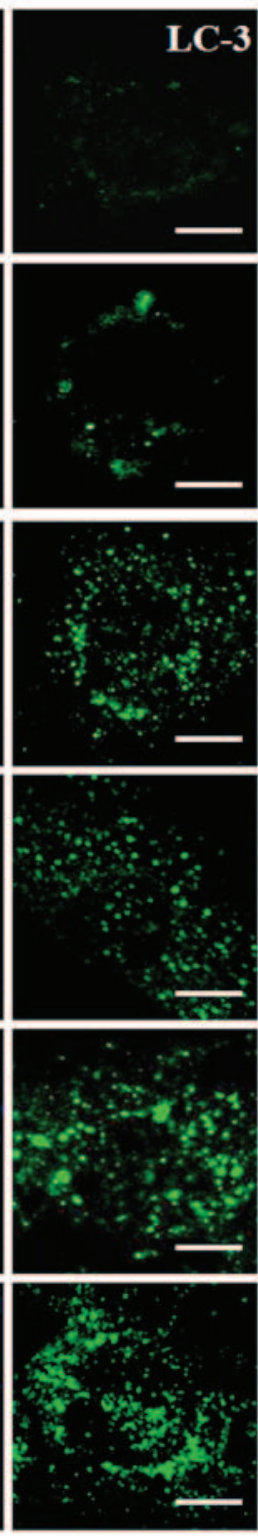
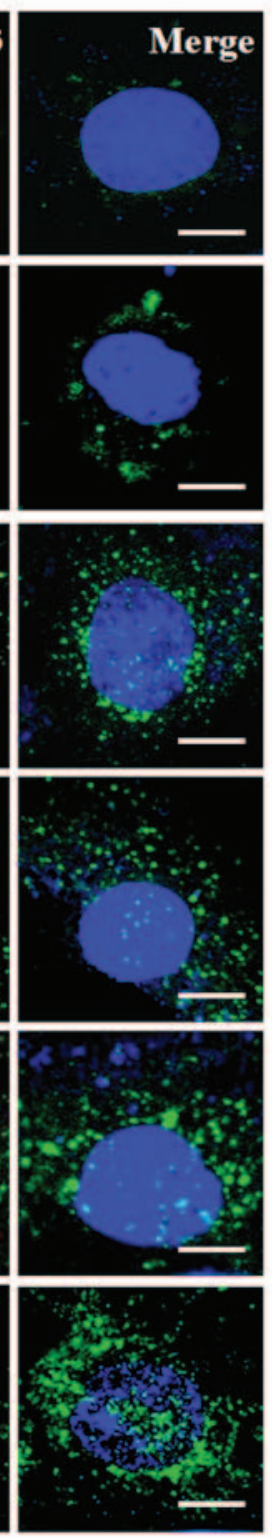

B

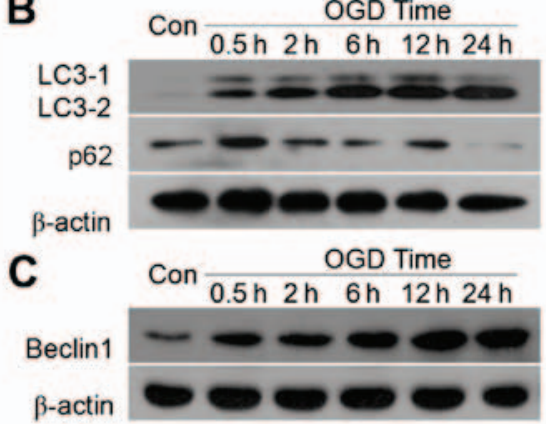

D

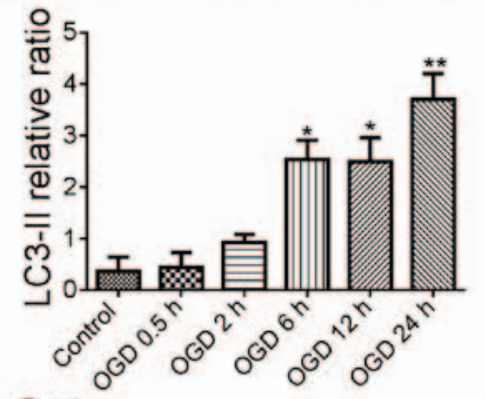

E

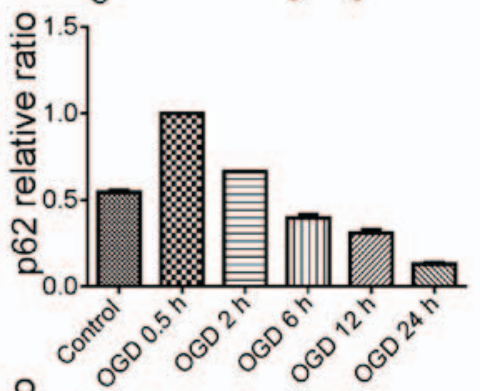

$\mathbf{F}$

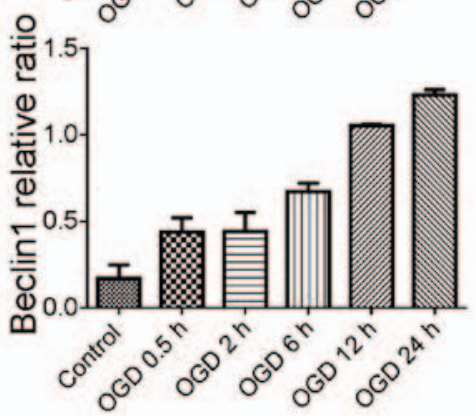

Figure 1. Autophagy in PC12 cells following IH. (A) Autophagosomes (green) in PC12 cells at various OGD treatment times (LC3 immunolabeling). IH induced autophagy in the PC12 cells. The number of autophagosomes increased with OGD in a time-dependent manner. Scale bar, $30 \mu \mathrm{m}$. Expression of (B) LC3-II, p62 and (C) Beclin 1, determined using western blot analysis. The expression levels of LC3-II and Beclin 1 increased in a time-dependent manner, and the expression of p62 decreased in time-dependent manner. Grayscale ratios of LC3-II, p62 and Beclin 1 (target protein/ $\beta$-actin) are shown in histograms. (D) Expression of LC3-II increased significantly from OGD $6 \mathrm{~h}$ in a time-dependent manner, (E) expression of p62 decreased from OGD $0.5 \mathrm{~h}$ in a time-dependent manner (F) Expression of Beclin 1 was similar to that of LC3-II. OGD groups differed significantly from the control with time-dependency. ${ }^{*} \mathrm{P}<0.05$ and ${ }^{* *} \mathrm{P}<0.01$ vs. control group. Data are expressed as the mean \pm standard error of the mean of four independent experiments. IH, ischemia-hypoxia; OGD, oxygen-glucose deprivation; LC3, microtubule-associated protein 1A/1B-light chain 3; Con, control.

was increased in the 3-MA+OGD group and decreased in the RAP+OGD group, compared with the OGD group with statistical significance (Fig. 3E). Cell viability was decreased in the 3-MA+OGD group and increased in the RAP+OGD group, compared with the OGD group with statistical significance (Fig. 3F).

Wnt signaling pathway and autophagy following $I H$. The Wnt pathway comprises canonical and noncanonical pathways. The present study further examined whether the canonical Wnt pathway was involved in IH-induced neuronal injury. The serial key proteins of the Wnt pathway, Wnt1, Wnt3a, Dvl2, $\beta$-catenin, C-myc and cyclin D1, were selected as targets for investigation using western blot analysis. Compared with the control, the expression levels of Wnt proteins in the PC12 cells were significantly activated during $\mathrm{IH}$, for example, expression of Wnt1 was increased in the OGD groups at $12 \mathrm{~h}$ (Fig. 4A and B), whereas the expression of Wnt3a was elevated in the OGD groups at $6 \mathrm{~h}$ (Fig. 4A and C). However, the expression levels of downstream proteins of the Wnt pathway, including $\beta$-catenin and Dvl2, were initially increased compared with those in the control, and then showed a decreasing trend with prolonging of OGD time (Fig. 4D and E). Similar results were observed in the expression levels of 


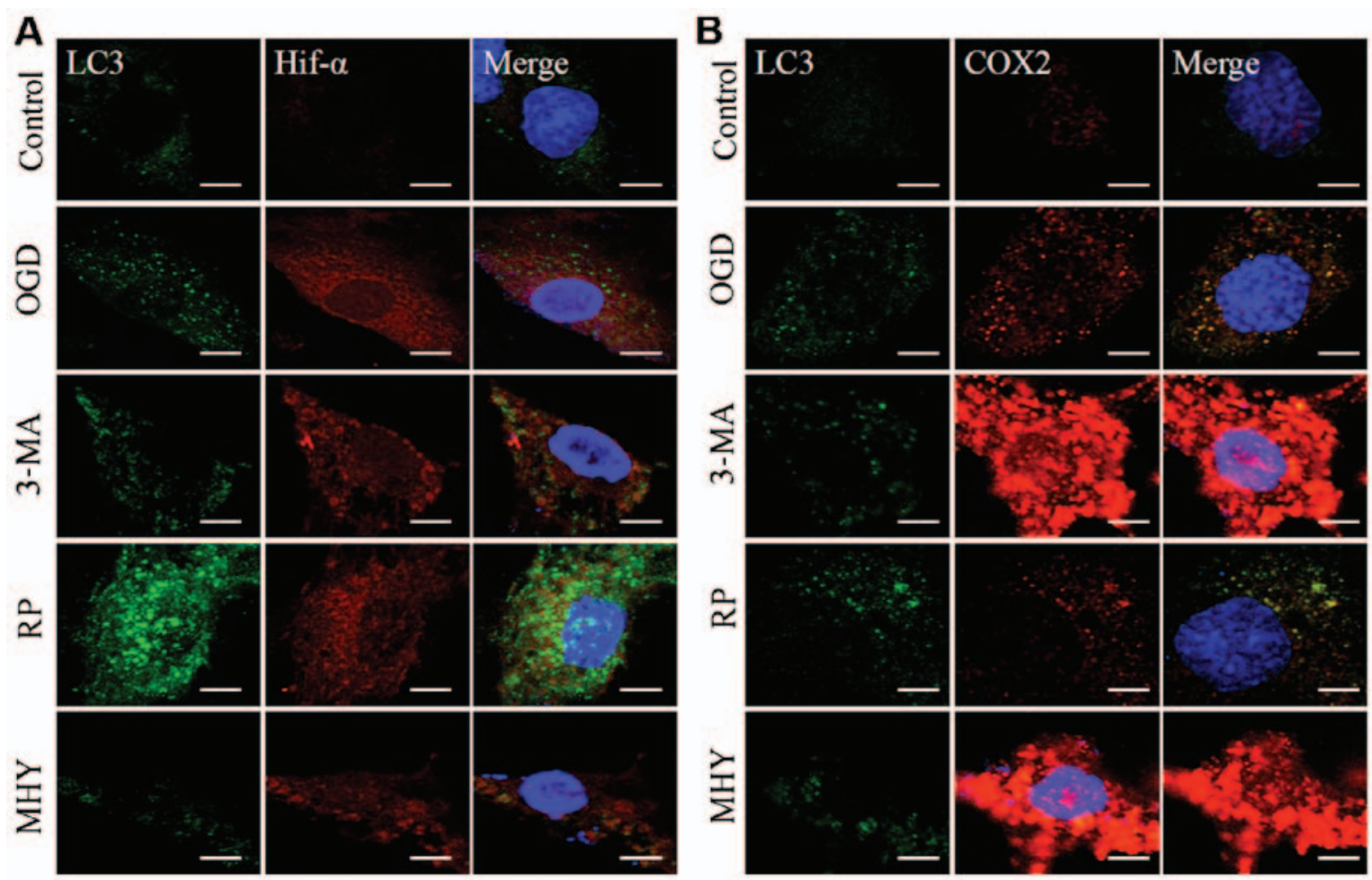

Figure 2. Chemical interventions of autophagy and ischemic-hypoxic injury, assessed using immunochemical double labeling. Compared with the control group, expression levels of HIF- $\alpha$ and COX2 were altered by chemical intervention. (A) Chemical intervention altered the expression of HIF- $\alpha$ and autophagosmes. Following autophagy antagonist (3-MA) intervention, expression of HIF- $\alpha$ was enhanced, compared with that in the OGD group, and was decreased by the autophagy agonist, rapamycin. In the MHY treatment group, expression of HIF- $\alpha$ was similar to that in the 3-MA group. (B) Chemical intervention showed changes in the expression of COX2 and autophagosomes. Changes in the expression of COX2 were similar to changes in HIF- $\alpha$. Scale bar, $30 \mu \mathrm{m}$. OGD, oxygen-glucose deprivation; HIF- $\alpha$, hypoxia-inducible factor- $\alpha$; COX2, cyclooxygenase 2; 3-MA, 3-methyladenine; RP, rapamycin; MHY, MHY1485.
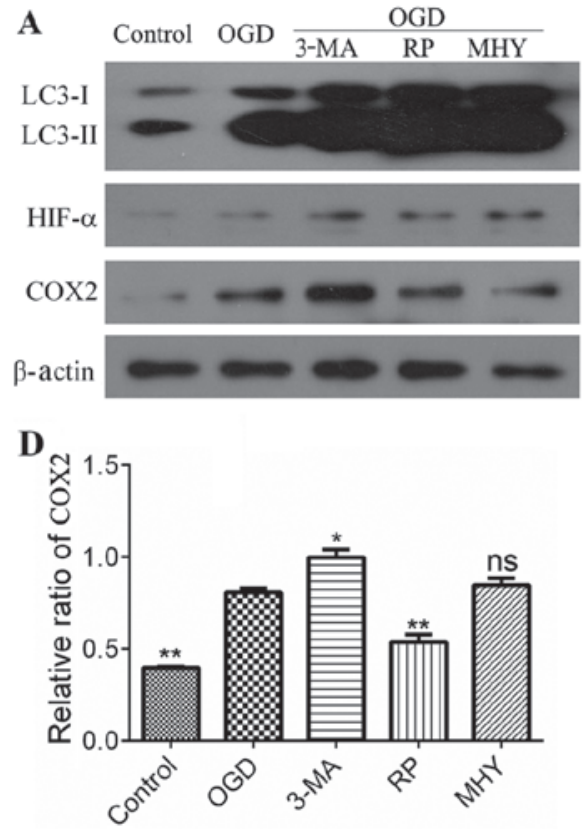

B

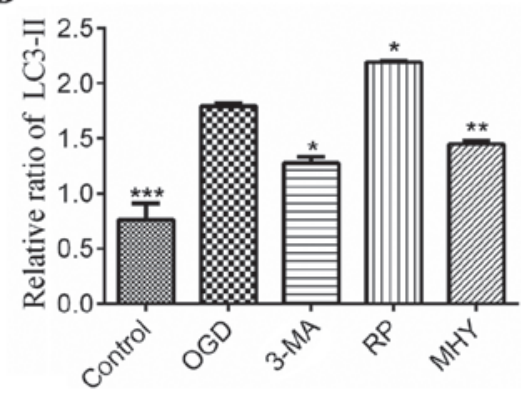

$\mathbf{E}$

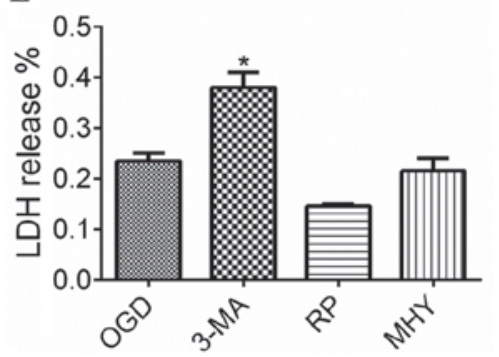

C

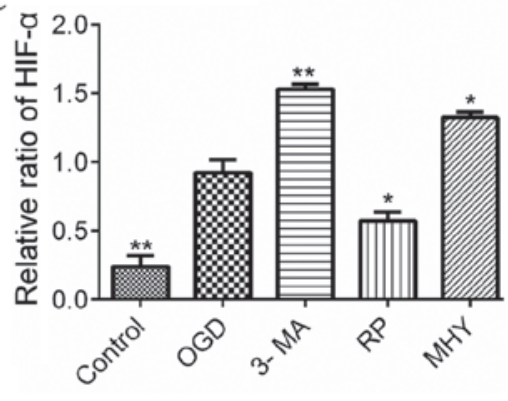

$\mathbf{F}$

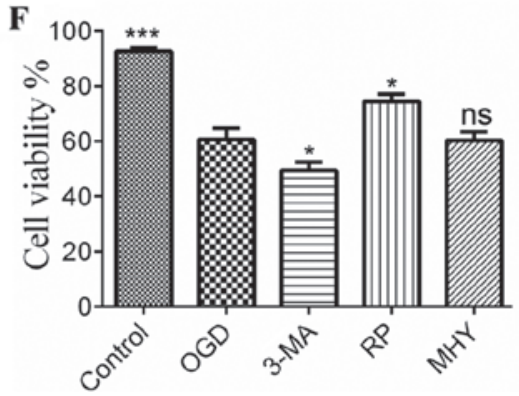

Figure 3. Statistical analysis of protein expression in different treatment groups following immunoblotting. (A) Expression of LC3, HIF- $\alpha$ and COX2. (B) Quantitative analyses of LC3-II, showed significant difference between the control and chemical intervention groups. ${ }^{*} \mathrm{P}<0.05$, ${ }^{* *} \mathrm{P}<0.01$ and ${ }^{* * * *} \mathrm{P}<0.001$ vs. control group $(\mathrm{n}=4)$. (C) Quantitative analysis of expression of HIF- $\alpha$, which showed significant differences between the control and chemical intervention groups. ${ }^{*} \mathrm{P}<0.05$ and ${ }^{* *} \mathrm{P}<0.01$ vs. control group $(\mathrm{n}=4)$. (D) Quantitative analysis of the expression of COX2, showed a significant difference between the control and chemical intervention groups. ${ }^{*} \mathrm{P}<0.05$ and ${ }^{* *} \mathrm{P}<0.01$ vs. control group ( $\left.\mathrm{n}=4\right)$. (E) Levels of LDH in were significantly increased in the 3-MA group, compared with the control. * $\mathrm{P}<0.05$ vs. control group. Data are presented as the mean \pm standard error of the mean of four independent experiments. (F) Cell viability in the chemical intervention groups. Viability was increased in the OGD+RP group, compared with the OGD group, and decreased in the 3-MA and MHY groups, compared with the OGD group. Data are presented as the mean \pm standard deviation of four independent experiments. ${ }^{*}<0.05$ and ${ }^{* * *} \mathrm{P}<0.001$ vs. control group. OGD, oxygen-glucose deprivation; COX2, cyclooxygenase 2; HIF- $\alpha$, hypoxia-inducible factor- $\alpha$; 3-MA, 3-methyladenine; RP, rapamycin; MHY, MHY1485; LDH, lactate dehydrogenase; ns, not significant. 
A

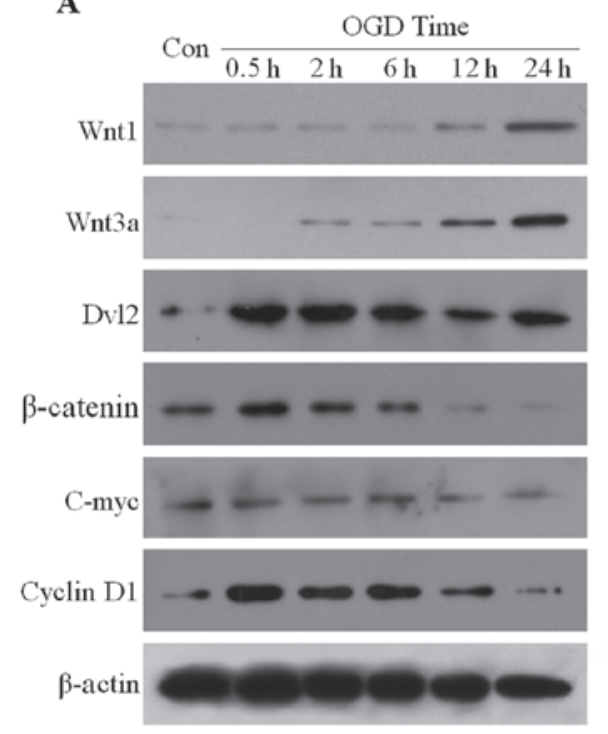

B
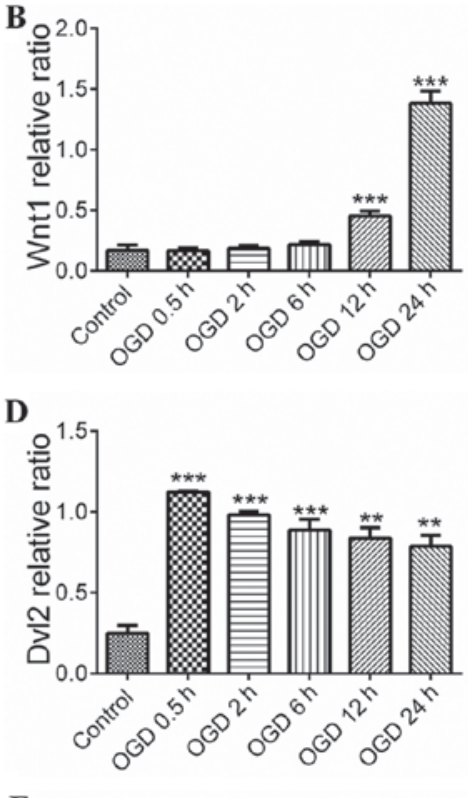

F

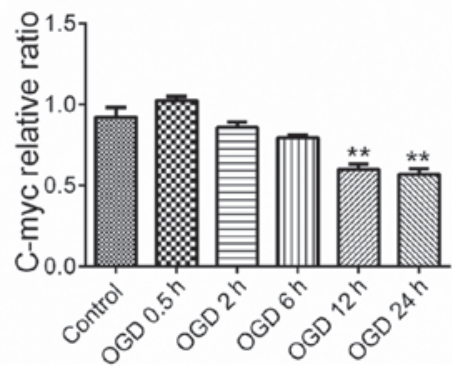

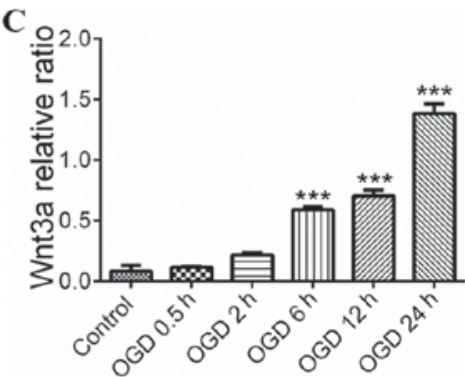

E 으

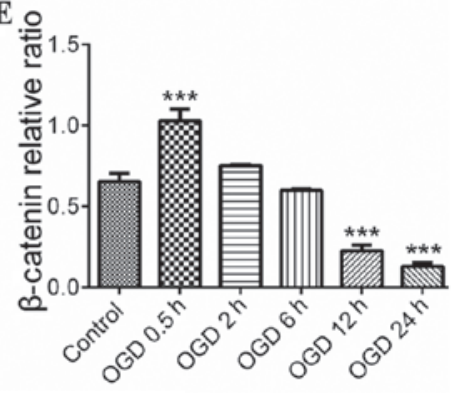

G

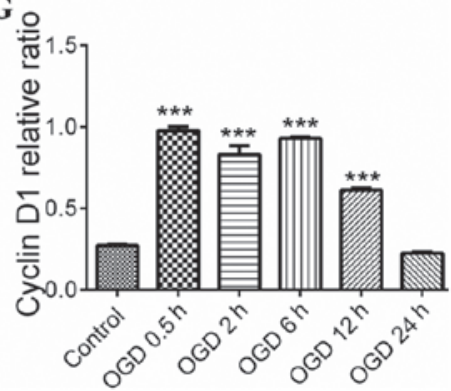

Figure 4. Wnt signaling pathway and ischemic-hypoxic injury over time. (A) Expression levels of Wnt1, Wnt3a, Dvl2, $\beta$-catenin, C-myc and cyclin D1 were shown by immunoblotting. Expression levels of (B) Wnt1 and (C) Wnt3a in the OGD groups were increased with time, with significant differences in the OGD groups from 6 h. ${ }^{* * * *} \mathrm{P}<0.001$ vs. control group $(\mathrm{n}=4)$. Quantitative analyses showed the expression levels of (D) Dvl2, (E) $\beta$-catenin, (F) C-myc and (G) cyclin D1 increased initially compared with those in the control group, and then decreased with increased OGD time. Quantitative analyses of Dv12 and $\beta$-catenin showed there were significant differences in OGD at 0.5 h. ${ }^{* * *} \mathrm{P}<0.01$ and ${ }^{* * * *} \mathrm{P}<0.001$ vs. control group $(\mathrm{n}=4)$. Quantitative analyses of cyclin $\mathrm{D} 1$ and C-myc showed a significant difference between the OGD groups and control group. ${ }^{* *} \mathrm{P}<0.01$ and ${ }^{* * * *} \mathrm{P}<0.001$ vs. control group $(\mathrm{n}=4)$. All the target proteins were analyzed quantitatively. Data are expressed as the mean \pm standard error of the mean of four independent experiments. OGD, oxygen-glucose deprivation; Dvl2, dishevelled segment polarity protein 2; Con, control.

C-myc and cyclin D1 (target protein) (Fig. 4F and G). This suggested that the expression of downstream proteins in the Wnt pathway was negatively correlated with the activation of autophagy (Fig. 4A, D and E). As shown in Fig. 5, the increases in the expression levels of Wnt1 and Wnt3a were parallel with the activation of autophagy (Fig. 5A-C), and the statistical data confirmed the observations in the downstream proteins $(\mathrm{P}<0.05)$ (Fig. 5D and $\mathrm{E})$. The results indicated that the upstream proteins (Wnt1 and Wnt3a) were upregulated by the activation of autophagy in the IH process, whereas downstream proteins (Dv12, $\beta$-catenin, C-myc and cyclin D1) were downregulated by the activation of autophagy.

\section{Discussion}

Stroke is a common disease for which there is a lack of effective therapy (23-26). Detailed investigations have focused on this complex disease and advances have been made in the field. However, the mechanism remains to be fully elucidated, particularly the functions of autophagy during stroke $(2,27)$. Therefore, it is important to understand the mechanism and to develop novel treatments for stroke. In the present study, autophagy with respect to the Wnt signaling pathway in IH injury was investigated, in order to produce data to provide novel insight for stroke treatment.

Activation of autophagy with upregulation of autophagic flux in IH injury. The process of autophagy involves a series of autophagic membranous structures developing and evolving. LC3 is an essential protein in the autopahgic process, which is involved in the generation of autophagic vacuoles. Therefore, in investigations of autophagy, LC 3 is considered a marker of autophagosomes (25). Cells contain two types of LC3, which are $18 \mathrm{kDa}$ LC3-I and16 kDa LC3-II. The expression of LC3-II and ratio of LC3-II/LC3-I are positively associated with the number of autophagsomes and autophagic activity (21). Therefore, detecting the expression of LC3-I and LC3-II using LC3 immunofluorescence combined with western blot analysis enables assessment of the activation of autophagy. Beclin 1 is the homologue of yeasty Atg6 in mammals, in the Golgi apparatus, which is a specific autophagic protein. There is substantial evidence that Beclin 1 is involved not only in the formation of autophagosomes, but also in regulating the activity of autophagy $(28,29)$. When autophagy is activated, the expression of Beclin 1 is upregulated (30). p62 is the 
A

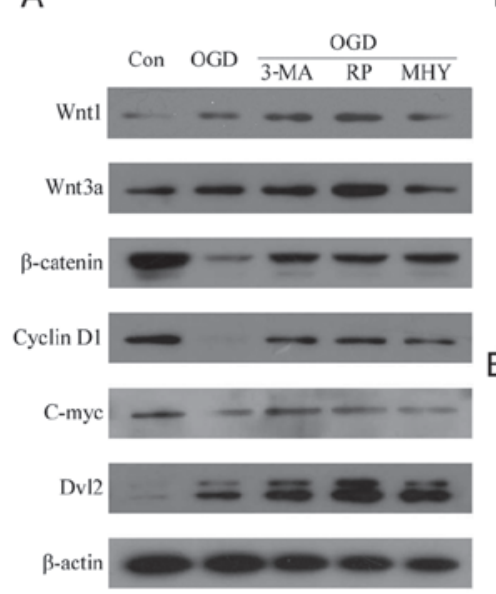

B

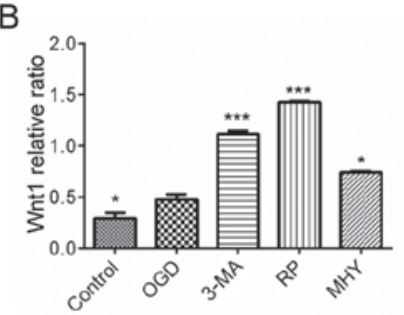

E

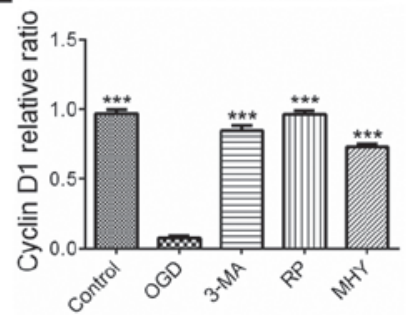

C

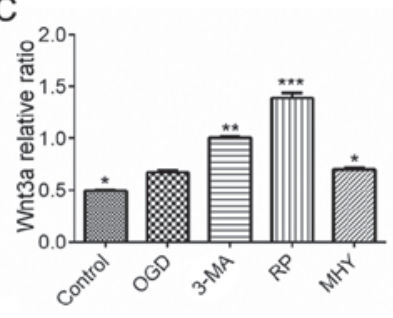

F

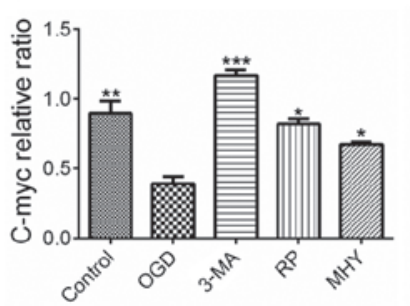

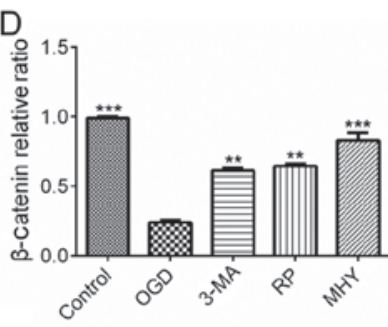

G

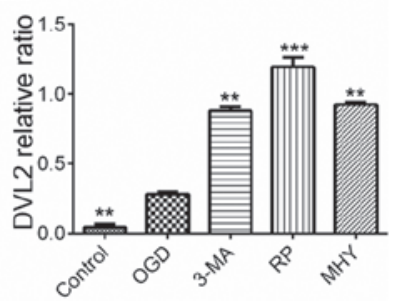

Figure 5. Wnt signaling pathway and autophagy following chemical intervention. Results of immunoblotting and statistical analysis. (A) Expression levels of Wnt1, Wnt3a, Dvl2, $\beta$-catenin, C-myc and cyclin D1 with different chemical interventions. Quantitative analyses of (B) Wnt1 and (C) Wnt3a showed significant differences between the chemical intervention groups and control group. ${ }^{*} \mathrm{P}<0.05,{ }^{* *} \mathrm{P}<0.01$ and ${ }^{* * *} \mathrm{P}<0.001$ vs. control group ( $\mathrm{n}=4$ ). Quantitative analysis of (D) $\beta$-catenin and (E) cyclin D1 showed significant differences between the chemical intervention groups and control group. ${ }^{* *} \mathrm{P}<0.01$ and ${ }^{* * *} \mathrm{P}<0.001$ vs. control group ( $n=4)$. Quantitative analysis of $(F) C$-myc and $(\mathrm{G})$ Dvl2 showed there were significant differences between the chemical intervention groups and control group. ${ }^{*} \mathrm{P}<0.05,{ }^{* *} \mathrm{P}<0.01$ and ${ }^{* * *} \mathrm{P}<0.001$ vs. control group $(\mathrm{n}=4)$. Data are expressed as the mean \pm standard error of the mean of four independent experiments. OGD, oxygen-glucose deprivation; Dvl2, dishevelled segment polarity protein 2; Con, control; 3-MA, 3-methyladenine; RP, rapamycin; MHY, MHY1485.

bridge between LC3 and ubiquitination substrate; autophagic vacuoles engulfing ubiquitination substrate require the assistance of p62 binding to the target proteins, forming polymer ubiquitinated proteins, which are engulfed by autophagosomes and then combine with lysosomes for degradation. Therefore, p62 is considered a marker of autophagic degradation. Under normal conditions, the levels of p62 increase when autophagy is inhibited, whereas levels decrease when autophagy is upregulated (31-37). In present study, the results of the immunofluorescence evaluation of LC3 revealed that the dispersed LC3-positive green dots gradually became aggregations of numerous green dots in the OGD groups. It is generally recognized that LC3-positive dots are diffuse in the cytoplasm when autophagy is inactive and are in an aggregated state with the activation of autophagy. The results of the present study indicated that autophagy was upregulated in OGD-induced permanent IH injury. In addition, the results of the western blot analysis confirmed that the expression of LC3-II was enhanced as OGD time extended, and the expression of Beclin 1 was similar to that of LC3. Therefore, the results indicated that autophagy was activated in OGD-induced permanent IH injury.

Following the activation of autophagy, autophagosomes gradually increase, however, evaluating whether the autophagosomes can be degraded successfully or not requires evaluation of a parameter, which can reflect the whole process of autophagy. Autophagic flux is considered the most reliable and widely recognized parameter reflecting the process of autophagy (9). Evaluating autophagic flux involves two aspects: Following the activation of autophagy, whether mature autophagosomes increase gradually or whether autophagosomes can combine with lysosomes and be degraded, resulting in a decrease in $\mathrm{p} 62$. In the present study, the results revealed that the ratio of LC3-II/I increased continuously, indicating that mature autophagosomes were increased with the activation of autophagy, and that autophagic flux was likely upregulated. The expression of p62 was negatively associated with increased OGD duration, which indicated that p62 was increasingly degraded and that autophagic flux was upregulated. Using lysosomal inhibitors to assess the LC3B-II/I ratio is considered the gold standard parameter to evaluate autophagic flux (38). The results of the present study showed that the ratio of LC3-II/I was markedly increased under OGD-induced permanent IH injury following use of the lysosomal inhibitor MHY1485. This indicated that autophagic flux was upregulated. Taken together, the results indicated that autophagy was activated and autophagic flux was upregulated in OGD-induced permanent IH injury.

Autophagy has a neuroprotective effect in IH injury. Whether IH induced-autophagy has a neuroprotective effect or induces injury is debated (39). Certain studies have revealed that autophagy is harmful during the neural $\mathrm{IH}$ process $(8,26,40)$, whereas other studies have demonstrated that the protective role of autophagy protects cells from death during injury $(4,11,41-44)$. In previous studies on the role of autophagy in IH encephalopathy, the majority focused on the role of autophagy in IH reperfusion, whereas relatively few focused on the role of autophagy in neuronal permanent $\mathrm{IH}$ injury, and the majority of lacked evaluation of autophagic flux. Therefore, in order to assess the role of autophagy in permanent IH injury and assess autophagic flux, evaluation of the autophagic effect on permanent IH injury is required. The present study demonstrated that autophagy was activated with the upregulation of autophagic flux, therefore, in order to further evaluate the change in IH injury by autophagy, IH injury was investigated in further experiments. The autophagy agonist rapamycin and antagonists 3-MA and MHY1485, were used to enhance or inhibit autophagy to assess changes in $\mathrm{IH}$ 
injury parameters, including the expression of pro-inflammatory factors COX2 and HIF- $\alpha$, the release of LDH and cell viability, to evaluate the role of autophagy in permanent $\mathrm{IH}$ injuries. The results showed that autophagy was enhanced with rapamycin administration and the expression of LC3 was increased. The expression levels of HIF- $\alpha$ and COX2 were decreased. Following the administration of 3-MA, the expression of LC3 decreased, and the expression levels of HIF- $\alpha$ and COX2 increased. This revealed that the upregulation of autophagy alleviated inflammation and cell hypoxia, whereas the inhibition of autophagy aggravated inflammation and cell hypoxia, indicating that autophagy has a possible protective role in OGD-induced permanent IH injury. On this basis, the present study aimed to understand how, if autophagic activity is altered, $\mathrm{LDH}$ release and cell viability change. It was found that the release of LDH was reduced in the OGD+Rap group, compared with that in the OGD group, and LDH release was increased in the OGD+3-MA group and OGD+MHY1485 group, compared with that in the OGD group. As LDH release is a parameter of cell injury, the results of the present study further confirmed that autophagy had a protective role in OGD-induce permanent IH injury. The results of the MTT assay showed that cell viability was enhanced in the OGD+Rap group, compared with that in the OGD group, and was decreased in the OGD+3-MA group and OGD+MHY1485 group, compared with that in the OGD group. Taken together, it was hypothesized that the upregulation of autophagy had a protective role in OGD-induced permanent IH injury.

Studies have indicated that three factors determine autophagic function, namely the level of activation, the time of induction and whether autophagic flux is impaired or not. A previous study found that, following the administration of the autophagy antagonist 3-MA at different phases, the function of autophagy was distinct. When 3-MA was administered at $24 \mathrm{~h}$ following $\mathrm{IH}$ reperfusion, autophagy was inhibited and neuron apoptosis was observed; however, when 3-MA was administered at $48-72 \mathrm{~h}$ following $\mathrm{IH}$ reperfusion, the inhibition of autophagy protected the cells from death (8). The reason for this may be that autophagy was excessively activated, resulting in a change in the role of autophagy from protective to damaging with the increase in IH reperfusion time. The present study focused on the time frame of $0.5-24 \mathrm{~h}$ OGD, and the results of 3-MA administration were similar to the study described above. Therefore, in the present study, the activation of autophagy was moderate, as autophagy was activated within $24 \mathrm{~h}$, therefore having a protective effect. Another study reported that 3-MA administration prior to middle cerebral artery occlusion led to aggregation following $\mathrm{IH}$ injury, whereas following preprocessing with rapamycin, the protection was similar to that following high pressure oxygen pretreatment, indicating that autophagy was activated at the early phase and had a protective effect $(31,45)$. In the present study, the autophagy agonist and antagonist were administered prior to OGD treatment of the cells; therefore, autophagy was activated at the early phase of IH injury, which was similar with the above study. Other studies have reported that whether autophagic flux is damaged or not can determine the function of autophagy (5). The present study demonstrated that autophagic flux was not damaged and was upregulated. Therefore, according to the results mentioned above, the present study showed that autophagy had a protective effect, which may be associated with the early activation of autophagy, its moderate activation, and that autophagic flux was not damaged.

Wnt/ $\beta$-catenin signaling pathway moderates autophagy in PC12 cells during IH injury. In mammalian cells, the Wnt/ $\beta$-catenin signaling pathway has a regulatory role in nervous system development, neuron proliferation and apoptosis. Wnt1 signaling proteins include two types: Wnt1 family and Wnt5a family proteins (46). Wnt1 family proteins include Wnt1, Wnt3a and Wnt7a, and the Wnt5a family proteins include Wnt4 and Wnt5a. Wnt1 family proteins can activate the canonical Wnt/ $\beta$-catenin pathway, and it has been shown that it is key in the nervous system and neural cell regulation by improving mitochondrial function and reducing the damage from by 6-hydroxydopamine in SH-SY5Y cells, having a protective effect (47). It has also been revealed that Wnt1 can mediate neural protection under oxidative stress and ischemic conditions (48).

Wnt/ $\beta$-catenin pathway activation and inhibition determines the occurrence of growth-related physiological and pathological processes and development, including maintaining homeostasis under damage/stress conditions (49). In addition, there is crosstalk between this pathway and other pathways, including the phosphoinositide-3-kinase and receptor tyrosine kinase pathway, resulting in the Wnt/ $\beta$-catenin pathway affecting the expression of their downstream proteins (50). Studies have revealed that the Wnt/ $\beta$-catenin pathway is involved in multiple neural activities and partial neurodegenerative disease, including neural induction, synaptogenesis, intracephalic neurogenesis, neuron repair and Alzheimer's disease regulation (51-54). However, one of the primary functions of autophagy is the maintenance of physiological and pathological homeostasis in cells. It has been reported that crosstalk exists between autophagy and the Wnt/ $\beta$-catenin pathway (55), however, in permanent IH injury, the regulatory association between autophagy and the $\mathrm{Wnt} / \beta$-catenin pathway remains to be fully elucidated and warrants investigation.

The present study investigated whether there is crosstalk between Wnt/ $\beta$-catenin pathway activation and autophagy in OGD-induced permanent IH injury. Representative upstream and downstream proteins of the $\mathrm{Wnt} / \beta$-catenin pathway were examined, and the results showed that the expression levels of upstream proteins Wnt1 and Wnt3a were gradually increased with increased OGD time, compared with those in the control group. The steady enhancement of their expression indicated that the $\mathrm{Wnt} / \beta$-catenin pathway began to activate. These results were similar to those of a previous study (56). However, the expression levels of mid-downstream proteins, Dvl2, $\beta$-catenin, C-myc and cyclin D1, were increased from OGD $0.5 \mathrm{~h}$, compared with those in the control group and exhibited a decreasing trend with increased OGD time. These results differed from those of a previous study (57). This was likely to be associated with autophagy being involved in the regulation of this process. A study by Gao et al showed that, in normal conditions, autophagy inhibited the $\mathrm{Wnt} / \beta$-catenin pathway, predominantly due to LC3 and Dvl2 interacting to increase the degradation of Dvl2 (55). In the present study, it was demonstrated in permanent IH injury that autophagy was activated from OGD $0.5 \mathrm{~h}$, and exhibited OGD time-dependency. This corresponded with the enhanced expression of Dvl2 at OGD 
$0.5 \mathrm{~h}$, which reduced gradually with increased OGD time. In the Wnt/ $\beta$-catenin pathway, the reduction of Dvl2 leads to the combination of Dvl2 and Axin decreasing, which renders the $\beta$-catenin degradation complex unable to depolymerize completely in plasma, resulting in a decrease in the activation of downstream proteins $(55,58)$. The results of the present study revealed the expression of downstream proteins of the Wnt pathway, Dvl2 and $\beta$-catenin, were initially increased, compared with those in the control, and then decreased with increased OGD time (Fig. 4D and E). Similar results were observed with C-myc and cyclin D1 (Fig. 4F and G). These results were as expected, and indicated that autophagy likely degraded Dvl2 to negatively regulate the Wnt/ $\beta$-catenin pathway.

The present study further investigated whether autophagy regulated the $\mathrm{Wnt} / \beta$-catenin pathway. The autophagy agonist and antagonist were used to regulate autophagic activity, and the expression of the proteins of the $\mathrm{Wnt} / \beta$-catenin pathway mentioned above were examined to determine whether expression was negatively associated with the degree of autophagic activation. The results showed that the expression of upstream proteins Wnt1 and Wnt3a were increased in accordance with the degree of autophagic activation. The expression levels of Dvl2, $\beta$-catenin, C-myc and cyclin D1 decreased as autophagy was upregulated, and their expression levels increased when autophagy was downregulated, which indicated that the expression of downstream proteins of the $\mathrm{Wnt} / \beta$-catenin pathway were negatively associated with the degree of autophagic activation. It has been reported that $\beta$-catenin can become the target protein of autolysosome degradation when autophagy is activated (59). Others have shown that $\beta$-catenin is selectively degraded, according to the formation of a $\beta$-catenin-LC3 complex, which attenuates the transcription of $\beta$-catenin to the downstream protein TCF and may assist in coping with metabolic stress (60). Therefore, it was hypothesized that autophagy negatively regulated the downstream proteins of the $\mathrm{Wnt} / \beta$-catenin pathway to assist in coping with IH stress, with autophagy and the $\mathrm{Wnt} / \beta$-catenin pathway having protective effects in cells.

In conclusion, the present study revealed that autophagy was upregulated with autophagic flux to protect cells from damage and death following IH. The $\mathrm{Wnt} / \beta$-catenin pathway was involved in regulation during $\mathrm{IH}$, and autophagy mediated the negative regulation of the $\mathrm{Wnt} / \beta$-catenin pathway. These findings indicated that the Wnt/ $\beta$-catenin pathway and autophagy offer potential as therapeutic targets for the treatment of IH neural injury.

\section{Acknowledgements}

This study was funded by the National Natural Science Foundation of China (no. 1204311), the Henan Province Higher Education Key Research Project funding Scheme (no. 18A310001).

\section{References}

1. Lozano R, Naghavi M, Foreman K, Lim S, Shibuya K, Aboyans V, Abraham J, Adair T, Aggarwal R, Ahn SY, et al: Global and regional mortality from 235 causes of death for 20 age groups in 1990 and 2010: A systematic analysis for the Global Burden of Disease Study 2010. Lancet 380: 2095-2128, 2012.
2. Donnan GA, Fisher M, Macleod M and Davis SM: Stroke. Lancet 371: 1612-1623, 2008.

3. Han ZB, Ren H, Zhao H, Chi Y, Chen K, Zhou B, Liu YJ, Zhang L, Xu B, Liu B, et al: Hypoxia-inducible factor (HIF)-1 alpha directly enhances the transcriptional activity of stem cell factor (SCF) in response to hypoxia and epidermal growth factor (EGF). Carcinogenesis 29: 1853-1861, 2008.

4. Wen Y, Zhai RG and Kim MD: The role of autophagy in Nmnat-mediated protection against hypoxia-induced dendrite degeneration. Mol Cell Neurosci 52: 140-151, 2013.

5. Yang Z, Zhao TZ, Zou YJ, Zhang JH and Feng H: Hypoxia Induces autophagic cell death through hypoxia-inducible factor $1 \alpha$ in microglia. PLoS One 9: e96509, 2014.

6. Ma L, Xu Y, Su J, Yu H, Kang J, Li H, Li X, Xie Q, Yu C, Sun L, et al: Autophagic flux promotes cisplatin resistance in human ovarian carcinoma cells through ATP-mediated lysosomal function. Int J Oncol 47: 1890-1900, 2015.

7. Clarke PGH and Puyal J: Autophagic cell death exists. Autophagy 8: 867-869, 2012.

8. Ginet V, Spiehlmann A, Rummel C, Rudinskiy N, Grishchuk Y, Luthi-Carter R, Clarke PG, Truttmann AC and Puyal J: Involvement of autophagy in hypoxic-excitotoxic neuronal death. Autophagy 10: 846-860, 2014.

9. Kroemer G and Levine B: Autophagic cell death: The story of a misnomer. Nat Rev Mol Cell Biol 9: 1004-1010, 2008.

10. Puyal J, Ginet V and Clarke PG: Multiple interacting cell death mechanisms in the mediation of excitotoxicity and ischemic brain damage: A challenge for neuroprotection. Prog Neurobiol 105: 24-48, 2013.

11. Wei K, Wang P and Miao CY: A double-edged sword with therapeutic potential: An updated role of autophagy in ischemic cerebral injury. CNS Neurosci Ther 18: 879-886, 2012.

12. Gomez-Cambronero J and Kantonen S: A river runs through it: How autophagy, senescence, and phagocytosis could be linked to phospholipase D by Wnt signaling. J Leukoc Biol 96: 779-784, 2014.

13. Holla S, Kurowska-Stolarska M, Bayry J and Balaji KN: Selective inhibition of IFNG-induced autophagy by Mir155- and Mir31-responsive WNT5A and SHH signaling. Autophagy 10: 311-330, 2014.

14. Kim W, Kim M and Jho EH: Wnt/ $\beta$-catenin signalling: From plasma membrane to nucleus. Biochem J 450: 9-21, 2013.

15. Petherick KJ, Williams AC,Lane JD, Ordóñez-Morán P, Huelsken J, Collard TJ, Smartt HJ, Batson J, Malik K, Paraskeva C, et al: Autolysosomal $\beta$-catenin degradation regulates Wnt-autophagy-p62 crosstalk. EMBO J 32: 1903-1916, 2013.

16. Clevers $\mathrm{H}$ and Nusse $\mathrm{R}$ : Wnt $/ \beta$-catenin signaling and disease. Cell 149: 1192-1205, 2012.

17. Inestrosa NC, Montecinos-Oliva C and Fuenzalida M: Wnt signaling: Role in Alzheimer disease and schizophrenia. J Neuroimmune Pharmacol 7: 788-807, 2012.

18. Shruster A, Ben-Zur T, Melamed E and Offen D: Wnt signaling enhances neurogenesis and improves neurological function after focal ischemic injury. PLoS One 7: e40843, 2012.

19. Chen JL, Lin HH, Kim KJ, Lin A, Ou JH and Ann DK: PKC delta signaling: A dual role in regulating hypoxic stress-induced autophagy and apoptosis. Autophagy 5: 244-246, 2009.

20. Petiot A, Ogier-Denis E, Blommaart EFC, Meijer AJ and Codogno P: Distinct classes of phosphatidylinositol 3'-kinases are involved in signaling pathways that control macroautophagy in HT-29 cells. J Biol Chem 275: 992-998, 2000.

21. Kabeya Y, Mizushima N, Ueno T, Yamamoto A, Kirisako T, Noda T, Kominami E, Ohsumi Y and Yoshimori T: LC3, a mammalian homologue of yeast Apg8p, is localized in autophagosome membranes after processing. EMBO J 19: 5720-5728, 2000.

22. Rubinsztein DC, Gestwicki JE, Murphy LO and Klionsky DJ: Potential therapeutic applications of autophagy. Nat Rev Drug Discov 6: 304-312, 2007.

23. Bodhankar S, Chen Y, Vandenbark AA, Murphy SJ and Offner H: PD-L1 enhances CNS inflammation and infarct volume following experimental stroke in mice in opposition to PD-1. J Neuroinflammation 10: 111, 2013

24. Wong KS, Wang Y, Leng X, Mao C, Tang J, Bath PM, Markus HS, Gorelick PB, Liu L, Lin W, et al: Early dual versus mono antiplatelet therapy for acute non-cardioembolic ischemic stroke or transient ischemic attack: An updated systematic review and meta-analysis. Circulation 128: 1656-1666, 2013.

25. Yang Z, Zhong L, Zhong S, Xian R and Yuan B: Hypoxia induces microglia autophagy and neural inflammation injury in focal cerebral ischemia model. Exp Mol Pathol 98: 219-224, 2015. 
26. Zhang X, Yuan Y, Jiang L, Zhang J, Gao J, Shen Z, Zheng Y, Deng T, Yan H, Li W, et al: Endoplasmic reticulum stress induced by tunicamycin and thapsigargin protects against transient ischemic brain injury: Involvement of PARK2-dependent mitophagy. Autophagy 10: 1801-1813, 2014

27. Pellegrini L, Bennis Y, Guillet B, Velly L, Bruder N and Pisano P: Cell therapy for stroke: From myth to reality. Rev Neurol (Paris) 169: 291-306, 2013 (In French).

28. Edinger AL and Thompson CB: Defective autophagy leads to cancer. Cancer Cell 4: 422-424, 2003.

29. Scarlatti F, Maffei R, Beau I, Codogno P and Ghidoni R: Role of non-canonical Beclin 1-independent autophagy in cell death induced by resveratrol in human breast cancer cells. Cell Death Differ 15: 1318-1329, 2008.

30. Liang XH, Jackson S, Seaman M, Brown K, Kempkes B, Hibshoosh $\mathrm{H}$ and Levine B: Induction of autophagy and inhibition of tumorigenesis by beclin 1. Nature 402: 672-676, 1999.

31. Bartlett BJ, Isakson P, Lewerenz J, Sanchez H, Kotzebue RW, Cumming RC, Harris GL, Nezis IP, Schubert DR, Simonsen A et al: p62, Ref(2)P and ubiquitinated proteins are conserved markers of neuronal aging, aggregate formation and progressive autophagic defects. Autophagy 7: 572-583, 2011.

32. Cui J, Bai XY, Shi S, Cui S, Hong Q, Cai G and Chen X: Age-related changes in the function of autophagy in rat kidneys Age (Dordr) 34: 329-339, 2012

33. Komatsu M and Ichimura Y: Physiological significance of selective degradation of $\mathrm{p} 62$ by autophagy. FEBS Lett 584: 1374-1378, 2010

34. Masiero E, Agatea L, Mammucari C, Blaauw B, Loro E, Komatsu M, Metzger D, Reggiani C, Schiaffino S and Sandri M: Autophagy is required to maintain muscle mass. Cell Metab 10 507-515, 2009

35. Nezis IP, Simonsen A, Sagona AP, Finley K, Gaumer S, Contamine D, Rusten TE, Stenmark H and Brech A: Ref(2)P, the Drosophila melanogaster homologue of mammalian p62, is required for the formation of protein aggregates in adult brain. J Cell Biol 180: 1065-1071, 2008.

36. Nixon RA, Wegiel J, Kumar A, Yu WH, Peterhoff C, Cataldo A and Cuervo AM: Extensive involvement of autophagy in Alzheimer disease: An immuno-electron microscopy study. J Neuropathol Exp Neurol 64: 113-122, 2005

37. Wang L, Gao C, Yao S and Xie B: Blocking autophagic flux enhances matrine-induced apoptosis in human hepatoma cells. Int J Mol Sci 14: 23212-23230, 2013.

38. Tanida I, Minematsu-Ikeguchi N, Ueno T and Kominami E: Lysosomal turnover, but not a cellular level, of endogenous LC3 is a marker for autophagy. Autophagy 1: 84-91, 2005.

39. Gabryel B, Kost A and Kasprowska D: Neuronal autophagy in cerebral ischemia - a potential target for neuroprotective strategies? Pharmacol Rep 64: 1-15, 2012

40. Chang CF, Huang HJ, Lee HC, Hung KC, Wu RT and Lin AM: Melatonin attenuates kainic acid-induced neurotoxicity in mouse hippocampus via inhibition of autophagy and $\alpha$-synuclein aggregation. J Pineal Res 52: 312-321, 2012.

41. Carloni S, Buonocore G, Longini M, Proietti F and Balduini W: Inhibition of rapamycin-induced autophagy causes necrotic cell death associated with $\mathrm{Bax} / \mathrm{Bad}$ mitochondrial translocation. Neuroscience 203: 160-169, 2012.

42. Papadakis M, Hadley G, Xilouri M, Hoyte LC, Nagel S, McMenamin MM, Tsaknakis G, Watt SM, Drakesmith CW, Chen R, et al: Tscl (hamartin) confers neuroprotection against ischemia by inducing autophagy. Nat Med 19: 351-357, 2013.

43. Scherz-Shouval R, Weidberg H, Gonen C, Wilder S, Elazar Z and Oren M: p53-dependent regulation of autophagy protein LC3 supports cancer cell survival under prolonged starvation. Proc Natl Acad Sci USA 107: 18511-18516,2010.

44. Wang P, Guan YF, Du H, Zhai QW, Su DF and Miao CY: Induction of autophagy contributes to the neuroprotection of nicotinamide phosphoribosyltransferase in cerebral ischemia. Autophagy 8: 77-87, 2012.
45. Yan W, Zhang H, Bai X, Lu Y, Dong H and Xiong L: Autophagy activation is involved in neuroprotection induced by hyperbaric oxygen preconditioning against focal cerebral ischemia in rats. Brain Res 1402: 109-121, 2011.

46. Gordon MD and Nusse R: Wnt signaling: Multiple pathways, multiple receptors, and multiple transcription factors. J Biol Chem 281: 22429-22433, 2006

47. Wei L, Ding L, Mo MS, Lei M,Zhang L, Chen K and Xu P: Wnt3a protects SH-SY5Y cells against 6-hydroxydopamine toxicity by restoration of mitochondria function. Transl Neurodegener 4: 11, 2015.

48. Zhang J, Götz S, Vogt Weisenhorn DM, Simeone A, Wurst W and Prakash N: A WNT1-regulated developmental gene cascade prevents dopaminergic neurodegeneration in adult En1(+/-) mice. Neurobiol Dis 82: 32-45, 2015.

49. L'episcopo F, Serapide MF, Tirolo C, Testa N, Caniglia S, Morale MC, Pluchino S and Marchetti B: A Wntl regulated Frizzled-1/ $\beta$-Catenin signaling pathway as a candidate regulatory circuit controlling mesencephalic dopaminergic neuron-astrocyte crosstalk: Therapeutical relevance for neuron survival and neuroprotection. Mol Neurodegener 6: 49-49, 2011.

50. Demagny H and De Robertis EM: Smad4/DPC4: A barrier against tumor progression driven by RTK/Ras/Erk and Wnt/GSK3 signaling. Mol Cell Oncol 3: e989133, 2015.

51. Hooper C, Killick R and Lovestone S: The GSK3 hypothesis of Alzheimer's disease. J Neurochem 104: 1433-1439, 2008.

52. Magdesian MH, Carvalho MM, Mendes FA, Saraiva LM, Juliano MA, Juliano L, Garcia-Abreu J and Ferreira ST: Amyloid-beta binds to the extracellular cysteine-rich domain of Frizzled and inhibits Wnt/beta-catenin signaling. J Biol Chem 283: 9359-9368, 2008

53. Sebastião AM, Colino-Oliveira M, Assaife-Lopes N, Dias RB and Ribeiro JA: Lipid rafts, synaptic transmission and plasticity: Impact in age-related neurodegenerative diseases. Neuropharmacology 64: 97-107, 2013.

54. Viti J, Gulacsi A and Lillien L: Wnt regulation of progenitor maturation in the cortex depends on Shh or fibroblast growth factor 2. J Neurosci 23: 5919-5927, 2003.

55. Gao C, Cao W, Bao L, Zuo W, Xie G, Cai T, Fu W, Zhang J, Wu W, Zhang X, et al: Autophagy negatively regulates Wnt signalling by promoting Dishevelled degradation. Nat Cell Biol 12: 781-790, 2010.

56. Chong ZZ, Shang YC, Hou J and Maiese K: Wnt1 neuroprotection translates into improved neurological function during oxidant stress and cerebral ischemia through AKT1 and mitochondrial apoptotic pathways. Oxid Med Cell Longev 3: 153-165, 2010.

57. Varela-Nallar L, Rojas-Abalos M, Abbott AC, Moya EA, Iturriaga $\mathrm{R}$ and Inestrosa NC: Chronic hypoxia induces the activation of the $\mathrm{Wnt} / \beta$-catenin signaling pathway and stimulates hippocampal neurogenesis in wild-type and APPswe-PS1 $\triangle \mathrm{E} 9$ transgenic mice in vivo. Front Cell Neurosci 8: 17, 2014

58. Zhou KK, Benyajati S, Le Y, Cheng R, Zhang W and Ma JX: Interruption of Wnt signaling in Müller cells ameliorates ischemia-induced retinal neovascularization. PLoS One 9: e108454, 2014

59. Zhang Y, Wang F, Han L, Wu Y, Li S, Yang X, Wang Y, Ren F, Zhai Y, Wang D, et al: GABARAPL1 negatively regulates Wnt/beta-catenin signaling by mediating Dvl2 degradation through the autophagy pathway. Cell Physiol Biochem 27: 503-512, 2011.

60. Choi SW, Song JK, Yim YS, Yun HG and Chun KH: Glucose deprivation triggers protein kinase $\mathrm{C}$-dependent $\beta$-catenin proteasomal degradation. J Biol Chem 290: 9863-9873, 2015.

This work is licensed under a Creative Commons Attribution-NonCommercial-NoDerivatives 4.0 International (CC BY-NC-ND 4.0) License. 